\section{AJAX-WYATT ELECTRIC FURNACE}

\author{
BY G. H. CLAMER \\ The Ajax Metal Co., Philadelphia.
}

The Ajax-Wyatt electric furnace is an induction furnace of the vertical ring type. An induction furnace is in reality merely a transformer with a single-turn secondary.

From the earliest days of the alternating-current transformer, it has been known that if such transformer were badly designed, namely, with insufficient core iron, or insufficient carrying capacity of the conductors, that losses would occur, due to the conversion of electrical energy into thermal energy.

Mr. Edwin A. Colby, of Newark, and Deferranti of England, each conceived the idea about the same time of so magnifying the heating effects in a transformer that an actual melting equipment resulted. To do this it was necessary to have a current path of sufficient resistance in proportion to the current flowing through it that actual melting, and superheating would take place. They accordingly constructed a transformer, on one leg of which was placed a primary coil, and a body of refractory material surrounded the opposite leg, in which was formed the channel, or groove, for containing liquid metal in the form of a single turn. In such a construction there was great magnetic leakage, hence, a low power factor.

Kjellin, a few years later, made a furnace of better transformer construction by placing his primary coil concentrically within the secondary coil, (the liquid metal bath). With this construction, having provided means for protecting the primary coil from the heat of the liquid metal, a much better power factor resulted. With this design of furnace, the power factor becomes relatively lower as the capacity of the furnace (size of ring) becomes greater. The Kjellin furnace was the first furnace of the induction type to meet with commercial success. Many patents and improvements have since been issued, such patents covering means for bettering the power factor, details of construction, and for two- or three-phase operation.

In Europe, the induction furnace is today largely in commercial use for steel melting, but in this country in such use it has met with very indifferent success due mainly to refractory troubles. Schneider, President of the Great Creusot Steel Works of France, and the Past President of the British Iron \& Steel Institute, first conceived the idea of constructing a furnace with a closed channel of constant dimensions, and hence constant resistance, and having a bath above such column of liquid metal, thus providing a hydraulic head. He constructed a furnace in accordance with this idea, but after spending a considerable amount of money on it, was forced to abandon it because of the destruction of the refractory material surrounding the secondary loop.

In the Schneider furnace one end of the secondary loop was joined to the main bath at a higher level than the other end, the idea being to promote circulation due to the natural tendency of heated bodies to rise because of the difference in density. By incorrect proportioning of the secondary loop of metal slow circulation, due to thermal effect alone, would result. Because of slow circulation and the rapid conversion of electrical energy into thermal energy in the secondary loop, known as the resistor, the refractory materials would soon be brought to a temperature at which they fuse.

The next step in the development of the furnace I am about to describe, was the invention of Dr. Carl Hering. Dr. Hering found that it was possible to so proportion a liquid metal resistor, that when the current flowing through it was of high density, a force of considerable magnitude exerted itself upon the

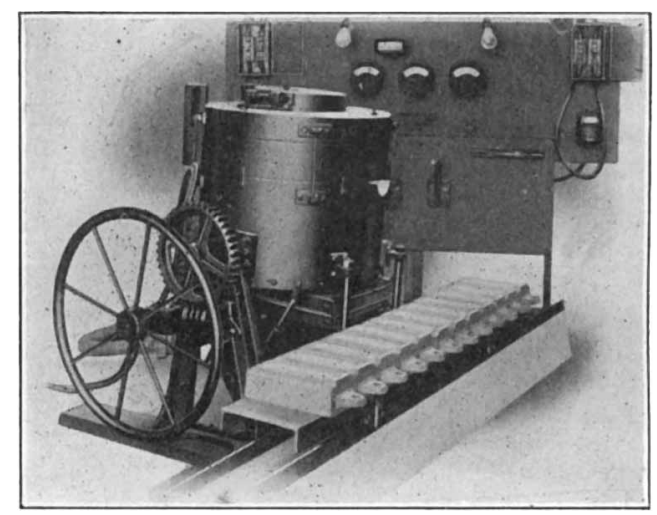

Fig. 1-Ajax-Wyatt Furnace

central section of such a column of liquid metal. By reason of this force, which he termed "pinch pressure," a rapid circulation would ensue, causing the liquid metal to be ejected from the center of the column and the cooler metal to flow into it at the periphery. By reason of the "pinch pressure" being exerted, the circulation becomes so rapid that overheating of the resistor walls does not result to nearly the same degree.

It is well-known that conductors in close proximity, and carrying current in the same direction, attract each other, whereas those carrying currents in the opposite direction repel each other.

Taking advantage of this phenomenon, Mr. James R. Wyatt added the further improvement of using this force, known as "motor effect," to circulate still more energetically the liquid metal in the resistor. By the very simple means of so constructing the resistor that it forms an acute angle, thereby causing the current to flow in opposite directions in the two legs of the triangle so formed, "motor effect" of considerable magnitude is set up at the angle. As the conductor (the liquid metal) is held in stationary walls the conductor cannot be bodily repelled, but the conductor being liquid is free to move and the metal is forced out of the resistor channel at the far sides, and 
the cooler metal flows in to take its place on the inner sides of these channels.

The Wyatt furnace is a furnace in which the resistor is preferably placed in a vertical position and the main bath above the resistor. In the resistor rapid circulation ensues because of the combined forces exerted therein, namely, "motor effect," "pinch effect," and "thermal effect." Each of these forces tends to force the metal upward. The strongest force exerted is that due to "motor effect" which is applied in greatest degree of force at the angle, which is so placed that it is at the extreme bottom of the furnace.
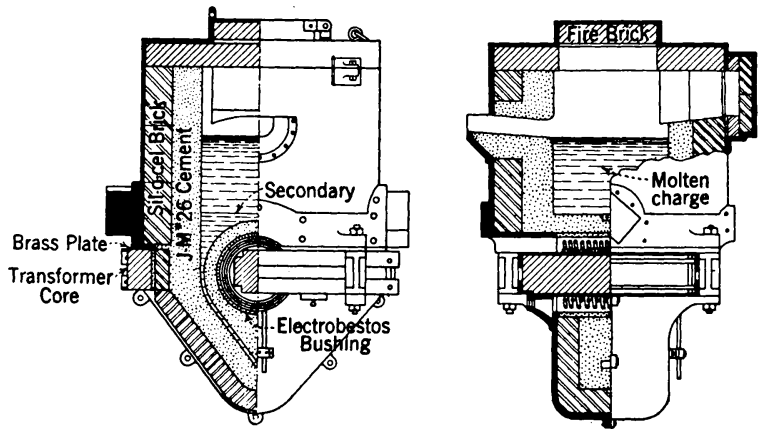

Fig. 2-Sectional Views of the Furnace

In such a furnace the heating and the stirring is all applied from the bottom (the logical place). No mechanical contrivance is necessary to produce circulation, or mixing. The conversion of electrical energy into thermal energy is 100 per cent, such transfer being accomplished in metal being heated. The heat losses are merely those due to radiation, and the small transformer losses.

The Ajax-Wyatt furnace has thus far been developed only for melting the copper-zinc alloys. It is possible to handle the full commercial range of such alloys as is used in rolling mill practise. Development work is progressing in adapting the furnace to other uses, and it is expected that it will shortly be possible to handle all the non-ferrous alloys in this furnace, and possibly some of the ferrous metals.

The characteristics of the Ajax-Wyatt furnace are the following:

1. Absolutely steady load.
2. Power factor-from 75 to 85 per cent, depending upon the size.

3. The metal is always the hottest part of the furnace.

4. No difficulty in getting required temperature for pouring.

5. Temperature under absolute control.

6. Thorough mixing without mechanical devices.

7. Due to shape of the hearth, or crucible, there is presented the smallest amount of exposed surface.

8. Lining cost per pound of metal melted, exceedingly small.

9. Requires minimum of attention.

10. The product of this furnace, because of the great uniformity and freedom from oxidation, is pronounced superior to that resulting from crucible, fuel-fired melting.

11. Efficiency on $60-\mathrm{kw}$. furnace, $11 \frac{1}{4}$ pounds melted per kilowatt-hour. With 100 per cent efficiency the melting rate would be $121 / 2$ pounds per kilowatt-hour. Melting efficiency therefore 90 per cent. This seems almost unbelievable, but it is the day in and day out melting rate of the furnace covering period during which millions of pounds have been melted.

12. Metal losses-absolute minimum.

The drawbacks of this furnace are:

1. Lack of flexibility, by which is meant that it must be started with a liquid charge, and a portion of the charge must always be held in the furnace. This makes it difficult to change from one mixture to another, notwithstanding the fact that the electrical regulation provided is sufficient to take care of any of the copper alloys.

2. The furnace should always be kept heated by keeping a sufficient amount of current on the furnace to supply the heat losses.

Nine kw. is a little more than sufficient for this purpose on a $60-\mathrm{kw}$. furnace.

For intermittent operation, the leads may be plugged to low-voltage taps and the furnace sealed up after placing a layer of charcoal on the metal, and thereafter it requires no attention and is immediately ready for maximum melting efficiency when recharged

\section{INTER-LABORATORY INSTRUMENT COMPARISONS}

During the past month the Bureau of Standards has cooperated in a comparison of the standards of the various laboratories of one of the largest electrical manufacturing concerns in the country. This company has laboratories in a number of cities of the United States and a set of instruments for measuring electrical current, voltage, and power was carried from one to another of these laboratories, and to the Bureau of Standards. The instruments were care- fully checked against the working standards of each laboratory. The results show a very gratifying agreement between the various plants and indicate that the standards in use by the electrical industry at large, so far as they are affected by this manufacturer, are satisfactorily uniform. The tests have also been of value in showing that the different types of instruments tested maintain their accuracy under various conditions of transportation. 